\title{
Ideação suicida na adolescência: um enfoque psicossociológico no contexto do ensino médio
}

\author{
Luciene da Costa Araújo - Universidade Federal da Paraíba, João Pessoa, Brasil \\ Kay Francis Leal Vieira ${ }^{1}$ - Universidade Federal da Paraíba, João Pessoa, Brasil \\ Maria da Penha de Lima Coutinho - Universidade Federal da Paraíba, João Pessoa, Brasil
}

\begin{abstract}
Resumo
Objetivou-se apreender as representações sociais da ideação suicida elaboradas por adolescentes do ensino médio, bem como investigar a presença deste fenômeno nesta população, considerando-se que a ideação suicida tem um importante valor preditivo para o ato suicida. Participaram 90 estudantes do ensino médio, os quais responderam ao Teste de Associação de Palavras, ao Inventário de Ideação Suicida de Beck e a um questionário sociodemográfico. Observou-se um índice de $22,2 \%$ de adolescentes com ideação suicida, havendo significativas diferenciações entre as representações elaboradas pelos grupos com e sem ideação suicida. Os adolescentes que apresentaram ideação se autorrepresentaram como pessoas sozinhas, associando a ideação a sentimentos de desesperança e solidão, ao mesmo tempo em que expressaram um pedido de ajuda diante de seu sofrimento. Os achados enfatizam a importância dos fatores sinalizadores, que podem permitir uma melhor compreensão sobre a problemática do suicídio.

Palavras-chave: Ideação suicida, Adolescência, Representação social, Ensino médio.
\end{abstract}

\section{Suicidal ideation in adolescence: a psychosociologic view in the high school context}

\begin{abstract}
The purpose of this study was to grasp the social representations about suicide amongst adolescents in high school context, as well as, to measure suicidal ideation levels among them, considering that suicide ideation brings a strong predictive role in suicide risk evaluation. Ninety high school students took part in the study. The inclusion criteria in the sample were: high school students aged between 14 and 22 years old. As instruments, the Free-Word Association Test, the Beck Scale for Suicide Ideation (BSI) and a sociodemographic questionnaire were used. A level of $22.2 \%$ of suicidal ideation sample and significant differences in social representations of suicidal behaviors were observed among adolescents with and without suicidal ideation. Adolescents with suicidal ideation self represented themselves as lonely, linking suicide ideations to hopelessness and loneliness, while requesting help for their suffering. Findings lay emphasis on factors that may allow a better understanding of the problem of suicide.
\end{abstract}

Keywords: Suicidal ideation, Adolescence, Social representation, High school.

$\mathrm{Na}$ literatura específica, com frequência o comportamento suicida é classificado em três categorias: ideação suicida, tentativa de suicídio e suicídio consumado. Segundo Werlang, Borges e Fensterseifer (2005), apesar de haver poucos dados disponíveis, alguns estudos clínicos e epidemiológicos sugerem a presença de possível gradiente de severidade e de heterogeneidade entre essas diferentes categorias. Assim, num dos extremos tem-se a ideação suicida (pensamentos, ideias, planejamento e desejo de se matar) e, no outro, o suicídio consumado, com a tentativa de suicídio entre eles.

Segundo Vega Piñero, Blasco, Baca-Garcia \& Diaz (2002), utiliza-se o termo parassuicídio, que significa condutas cuja intenção não é acabar com

1 Endereço para correspondência:

Rua João Soares Padilha, no 21 apto. 1103 - Bessa - João Pessoa-PB

E-mail: kayvieira@yahoo.com.br a própria vida, mas sim modificar o ambiente no qual o indivíduo está inserido. Esses comportamentos são característicos da adolescência e de pessoas imaturas, como forma de reação a um conflito, sendo diagnosticados, em numerosas ocasiões, como transtornos de personalidade e denominados de "chamadas de atenção", e em algumas ocasiões têm caráter de chantagem emocional.

Suicídio é uma palavra originada no latim, derivada da junção das expressões sui (si mesmo) e caederes (ação de matar). Num sentido geral, significa o ato voluntário por meio do qual o indivíduo possui a intenção e provoca a própria morte (Vieira, 2008). Apesar de não existir uma definição única aceitável, sabe-se que implica necessariamente um desejo consciente de morrer e a noção clara do que o ato executado pode resultar.

Segundo dados da OMS (2000), a taxa mundial de suicídio é estimada em torno de 16 por 100 mil habitantes, com variações conforme sexo, 
idade e país. Calcula-se que as tentativas sejam 20 vezes mais frequentes que o ato consumado. Botega (2007) ressalta que, em termos globais, a mortalidade por suicídio aumentou $60 \%$ nos últimos 45 anos; neste período, os maiores coeficientes mudaram de faixa etária - da mais idosa para a mais jovem, sendo esta considerada o grupo de maior risco em 30 países. A morte por suicídio passou a ocupar a terceira posição entre as causas mais frequentes de falecimento, na população de 15 a 44 anos de idade, em alguns países.

No Brasil, até há pouco tempo, o suicídio não era visto como um problema de saúde coletiva, pois entre as causas externas de mortalidades, encontrava-se na sombra dos elevados índices de homicídio e de acidentes de trânsito, 7 e 5 vezes maiores, respectivamente, em média (Botega, Werlang, Cais \& Macedo, 2006). Neste país, a taxa oficial de mortalidade por suicídio é estimada em 4,1 por 100 mil habitantes para a população como um todo, estando, para o sexo masculino, em torno de 6,6 e em 1,8 para o sexo feminino, o que o deixa no grupo de países os quais apresentam baixas taxas de suicídio. No entanto, por tratar-se de um país populoso, encontra-se entre os dez com números absolutos nesses casos, configurando um total de 7.987 casos em 2004 (Brasil, 2006).

Entretanto, sabe-se que as estatísticas sobre os atos suicidas são falhas e subestimadas, uma vez que o número que consta nas estatísticas oficiais é extraído das causas de morte assinaladas nos atestados de óbito. Porém, estes nem sempre são confiáveis, pois tanto a família quanto a própria sociedade, comumente, pressionam para que a causa seja falsificada. De acordo com Cassorla (1998), certamente a subestimação estatística será mais intensa quando se trata de crianças e adolescentes, em que os atos autodestrutivos serão negados ou até escondidos pela família, diante de maiores sentimentos de culpa e/ou vergonha pelo ato.

A subestimação das estatísticas sobre atos suicidas deve-se a vários fatores, principalmente, às dificuldades de conceituação. Dentre estas, por exemplo, destacam-se as de identificar com precisão: quando um acidente automobilístico foi uma fatalidade ou tentativa de suicídio; ou quando um usuário de drogas falece por over dose; assim como, quando um paciente nega-se a realizar o tratamento de suas patologias; ou quando se recusa a comer, podendo ser compreendido como abandono da vida.
Segundo Stevenson (1992), há uma tendência para o sub-relato de suicídios, que reflete, indubitavelmente, em algum grau, a tentativa de poupar aos membros da família um trauma emocional desnecessário. Além disso, a morte por suicídio pode ter impacto sobre certos temas legais, tais como benefícios obtidos por seguros. Mais ainda, Prieto e Tavares (2005) evidenciam que, desde o ano de 1975, a Organização Mundial de Saúde já ressaltava a possibilidade de que as diferenças entre as taxas de incidência de suicídio, entre os diversos países devessem-se, em grande parte, à falta de uniformidade nos procedimentos de notificação. Segundo a OMS (2000), se os mesmos métodos e regras para verificar se uma morte ocorreu ou não por suicídio fossem aplicados em todos os países, poder-se-ia assegurar com confiança que as diferenças dos índices refletem variações da incidência do fenômeno.

De acordo com Holmes (2001), as mulheres são três vezes mais propensas a tentarem o suicídio do que os homens, embora estes sejam três vezes mais bem-sucedidos em suas tentativas. A razão para essa diferença ainda não está bem definida, mas acredita-se que, no primeiro caso, isso se deva a elas serem mais tendenciosas a sofrer de depressão do que eles, reconhecendo-se, assim, o importante papel desempenhado pela depressão diante dos atos suicidas. Porém, no segundo caso, a hipótese destacada para explicar a diferença entre mulheres e homens é que estes usam técnicas mais violentas (revólveres, saltos de prédio) do que aquelas (overdose, corte dos pulsos, ingestão de medicamentos), aumentando assim, as chances das tentativas por eles utilizadas serem bem-sucedidas.

Conforme Barros, Coutinho, Araújo \& Castanha (2006), tem-se observado, nas últimas décadas, que o comportamento suicida tem aumentado entre os jovens, sendo a adolescência uma fase bastante associada à morte por causas violentas. É um período do desenvolvimento marcado por diversas modificações biológicas, psicológicas e sociais; e essas mudanças, geralmente, são acompanhadas de conflitos e angústias. Às vezes, quando expostos às intensas e prolongadas situações de sofrimento, de desorganização, os adolescentes podem desenvolver patologias e tornar-se mais vulneráveis ao suicídio (Teixeira \& Luís, 1997). É, também, nesse período que tanto as ideações quanto às tentativas ganham uma maior proporção, quando associadas ao quadro 
depressivo, embora essa situação não se restrinja somente à adolescência.

Igualmente nesse período há uma melhor compreensão a respeito da morte pelo desenvolvimento do pensamento abstrato; portanto, é importante que se verifique a presença da ideação suicida, já que esta pode ser considerada como um antecedente a uma a possível culminância do ato suicida (Turecki, 1999; Silva \& cols., 2006). Assim diante de um jovem que pensa, faz ameaças, tenta ou consuma o ato suicida, observa-se um colapso nos seus mecanismos adaptativos, os quais visam aliviar o sofrimento (Borges \& Werlang, 2002).

A prevenção do suicídio, tanto no nível individual quanto coletivo, dá-se mediante o reforço dos fatores ditos protetores, bem como pela diminuição dos de risco. Risco, segundo Benincasa e Rezende (2006), é um conceito da Epidemiologia Moderna e refere-se à probabilidade da ocorrência de algum evento indesejável. Os fatores de risco são elementos com grande probabilidade de desencadear ou associarse ao desenvolvimento de um evento indesejado, não sendo, necessariamente, o fator causal. Já os fatores de proteção são recursos pessoais ou sociais que atenuam ou neutralizam o impacto do risco.

$\mathrm{Na}$ literatura científica, os fatores de proteção são pouco mencionados, enquanto os de riscos são mais abordados e, dentre estes, os principais, segundo Botega e cols. (2006), são: transtornos mentais, perdas recentes, ou de figuras parentais na infância; dinâmica familiar conturbada; personalidade com fortes traços de impulsividade e agressividade; certas situações clínicas (como doenças crônicas incapacitantes, dolorosas, desfigurantes); ter acesso fácil a meios letais.

Alguns fatores sociodemográficos indicam que os indivíduos com probabilidade de maior risco de suicídio são: do sexo masculino, na faixa etária entre 15 e 35 anos ou acima de 75 anos, em condições econômicas extremas (muito ricos ou muito pobres), residentes em áreas urbanas, desempregados (principalmente perda recente do emprego), aposentados, ateus, solteiros ou separados e migrantes (WHO, 2003). Um dos grupos de maior risco é o dos indivíduos que já tentaram cometer suicídio em algum momento de suas vidas, e estima-se que a probabilidade seja 100 vezes maior nesse grupo do que na população em geral. Estudos têm demonstrado que a adesão desses indivíduos ao tratamento é baixa, mas que, por outro lado, existem estratégias eficazes para evitar novas tentativas (Botega \& cols., 2006). Já as pessoas com histórico de suicídio na família são mais propensas a se matar. De acordo com Solomon (2002), isso ocorre porque esse ato torna o impensável pensável e a dor de viver quando alguém que se ama aniquilou-se pode ser quase intolerável.

A ideação suicida, objeto de análise da presente pesquisa, também é considerada um fator de risco para o comportamento suicida. Alguns estudos a associam ao risco de tentativas e estimase que $60 \%$ dos indivíduos que consumaram o ato tinham-no idealizado previamente (Silva \& cols., 2006). Werlang, Borges e Fensterseifer (2005) a consideram uma característica frequente no período da adolescência, pois faz parte do processo de desenvolvimento de estratégias, que são forma de lidar com problemas existenciais como, por exemplo, compreender o sentido da vida e da morte.

No que se refere aos fatores de proteção do suicídio, destacam-se os seguintes: pessoas que possuem bons vínculos afetivos; sensação de estar integrado a um grupo ou comunidade; religiosidade; estar casado ou com companheiro fixo; ter filhos pequenos. A religiosidade representa um importante papel na prevenção do suicídio, pois foi comprovado que os indivíduos com maior envolvimento religioso apresentam menores taxas de suicídios; ela também é apontada como auxiliar no enfrentamento de doenças graves. Entre os muçulmanos, as taxas de suicídio são mais baixas quando comparadas às outras religiões, provavelmente por causa do pesado julgamento moral sobre o suicídio e consequente senso de punição, além de outras características culturais, como, por exemplo, a proibição do consumo de álcool (Botega \& cols., 2006).

Entende-se que a ideação suicida prediz o ato e por isso faz-se necessário não só a detecção precoce desses pensamentos, como também um maior entendimento a respeito dos motivos causadores do seu surgimento e das características peculiares desse período. A intensidade desses pensamentos, profundidade, duração, contexto em que surgem e a impossibilidade de desligar-se deles são fatores que distinguem o indivíduo saudável de um que se encontra à margem de uma crise suicida (WHO, 2003).

Para o desenvolvimento do presente estudo, utilizou-se o aporte teórico/metodológico da Teoria das Representações Sociais (TRS) desenvolvida pelo francês Serge Moscovici, partindo-se do pressuposto de que o grupo 
pesquisado, no caso os estudantes do ensino médio, tem um conhecimento socialmente construído que o permite elaborar um conhecimento prático acerca do suicídio. Estudar essa temática, na perspectiva das representações sociais, significa analisá-la não apenas através dos aportes teóricos, normativos e científicos, mas com vista a um novo olhar, voltado para a construção de um conhecimento prático e compartilhado por um determinado grupo de pertença. Sendo assim, será possível perceber como essas representações emergem os significados e as relações que estabelecem entre si, e em que medida uma determina a outra (Coutinho, 2005).

A Teoria das Representações Sociais é uma forma sociológica de psicologia social, originada na Europa por Serge Moscovici (1961), através da publicação de seu estudo La psychanalyse: son image et son public. Segundo Farr (1998), ela difere, marcadamente, das formas psicológicas de psicologia social, que são atualmente predominantes nos Estados Unidos da América. Esse contraste ocorre entre uma tradição de pesquisa europeia e uma americana de psicologia social moderna. Conforme Jodelet (2001), a representação social é uma forma de conhecimento socialmente elaborada e partilhada com um objetivo prático, que contribui para a construção de uma realidade comum a um conjunto social. Igualmente, designada como saber de senso comum ou ainda saber ingênuo, natural, essa forma de conhecimento é diferenciada, dentre outras, do conhecimento científico.

A representação social refere-se à maneira do indivíduo pensar e interpretar o cotidiano, ou seja, constitui-se em um conjunto de imagens, dotado de um sistema de referência que o permite interpretar sua vida e a ela dar sentido. A elaboração e funcionamento de uma representação podem ser compreendidos por meio dos processos de objetivação e ancoragem, que compreendem a imbricação e a articulação entre a atividade cognitiva e as condições sociais em que são forjadas as representações.

Jodelet (2001) afirma que a objetivação é o processo pelo qual o indivíduo reabsorve um excesso de significações, materializando-as; ou seja, é a construção formal de um conhecimento pelo indivíduo. Já a ancoragem, como instrumento do saber, é uma modalidade que permite compreender como os elementos de representação não só exprimem relações sociais, mas também contribuem para construí-las. Portanto, ela assegura o elo entre a função cognitiva de base da representação e a social, bem como fornece à objetivação os elementos imaginativos para servir na elaboração de novas representações.

Inicialmente, conforme o modelo proposto por Moscovici, as representações sociais possuíam duas funções: formação de condutas e orientação das comunicações sociais. Posteriormente, Abric (1994) acrescentou outras duas funções às representações, demonstradas pela evolução das pesquisas realizadas a propósito das cognições e práticas sociais; foram elas: a função identitária, que permite salvaguardar a imagem positiva do grupo e sua especificidade; e a função justificadora, que permite aos atores manterem ou reforçarem os comportamentos de diferenciação social, nas relações entre grupos (Nóbrega, 2001).

Segundo Vala e Monteiro (2004), as representações sociais apresentam uma dimensão funcional e prática, que acaba por ser evidente na organização dos comportamentos das atividades comunicativas, na argumentação e explicação cotidianas, e na diferenciação dos grupos sociais. Enquanto uma modalidade de conhecimento particular, a representação social tem por função a orientação de comportamentos e a facilitação da comunicação entre os indivíduos; considerando a indissociabilidade entre a experiência subjetiva e a inserção social dos sujeitos. Por conseguinte, as representações sociais dos adolescentes pesquisados, sobre os transtornos psicoafetivos podem ser compreendidas como uma interpretação coletiva da realidade vivida e falada por aquele grupo social, direcionando comportamentos e comunicações.

Desse modo, identificar as representações sociais acerca do comportamento suicida é compreender as formas que as pessoas utilizam para criar, transformar e interpretar essas problemáticas vinculadas à sua realidade, como também, conhecer seus pensamentos, sentimentos, percepções, experiências de vida compartilhadas e destacadas nas modalidades diferenciadas de comunicação; de acordo com o contexto cultural e a classe social a que pertencem, e as instituições às quais se está vinculado; prolongando-se para além das dimensões intrapsíquicas e concretizando-se em fenômenos sociais palpáveis de serem identificados e mapeados (Coutinho, 2005).

O presente estudo teve como objetivo apreender as representações sociais acerca do comportamento suicida elaboradas por estudantes do ensino médio matriculados em escolas públicas do estado da Paraíba; bem como 
investigar o índice epidemiológico da ideação suicida entre a população estudada.

\section{Método}

Trata-se de uma pesquisa de campo, ancorada em uma abordagem multimétodo de cunho qualitativo e quantitativo, fundamentada nos aportes teóricos e metodológicos das representações sociais. A amostra foi intencional e acidental, do tipo não-probabilística, constituída por 90 (noventa) estudantes do ensino médio, regularmente matriculados em uma escola da rede pública de ensino do município de João PessoaPB. A escolha dos participantes ocorreu pelo fato de ser o período da adolescência caracterizado por um alto e crescente índice de ideação suicida, conforme demonstra a literatura especializada já descrita anteriormente. As idades dos participantes variaram entre 14 e 18 anos $(M=16,67 ; D P=1,29)$, sendo a maioria desses do sexo feminino $(57,7 \%)$.

$\mathrm{O}$ desenvolvimento da pesquisa seguiu a orientação da Resolução CNS/Ministério da Saúde, $\mathrm{n}^{\circ}$ 196, de 10 de outubro de 1996. Para tanto, obteve-se a aprovação do Comitê de Ética do Centro de Ciências da Saúde, da Universidade Federal da Paraíba (CCS/UFPB), com o cadastro no Sistema Nacional de Informações sobre Ética em Pesquisas envolvendo Seres Humanos, do Ministério da Saúde, sob o protocolo n ${ }^{\circ}$ 1.086/07.

Foi realizado contato prévio com o diretor da instituição, apresentando-lhe os objetivos da pesquisa. Depois de recebida a autorização oficialmente assinada pela instituição, também foi solicitado que os pais dos estudantes assinassem o Termo de Consentimento Livre e Esclarecido, de acordo com as normas da resolução 196/96 sobre pesquisa envolvendo seres humanos, sendo previamente informados a respeito dos objetivos e procedimentos da pesquisa, bem como da confidencialidade dos dados e do anonimato dos participantes.

Para a obtenção dos dados utilizou-se a Escala de Ideação Suicida de Beck - BSI, a Técnica de Associação Livre de Palavras e o Questionário Biossociodemográfico. O primeiro instrumento é uma versão de autorrelato constituída por 21 itens, dos quais 19 apresentam três alternativas de respostas e refletem gradações da gravidade dos desejos, das atitudes e dos planos suicidas. Já os dois últimos, de caráter informativo, não incluídos no escore final, fornecem importantes subsídios sobre o paciente a respeito do número de tentativas prévias de suicídio e quanto à seriedade da intenção de morrer na última delas (Cunha, 2001).

A BSI foi estruturada de forma a permitir que os cinco primeiros itens pudessem ser usados como triagem da ideação suicida. Assim sendo, se a resposta do participante for 0 ao grupo de afirmações 4 - "indicando ausência de intenção ativa” ou ao grupo de número 5 - "indicando evitação de morte, se confrontado com uma situação ameaçadora para a vida" - ele deverá ser orientado a passar imediatamente ao item 20, deixando de dar resposta aos 14 seguintes. Estes, segundo a citada autora, são mais específicos, a respeito de planos e atitudes, com uma intenção suicida subjacente. Caso contrário, o examinando fará escolhas referentes aos grupos de afirmações dos itens 6 a 19. Quanto ao item 20, deve ser respondido por todos os examinandos, tenham ou não preenchido os 14 anteriores. Já o item 21 só será respondido por sujeitos com história de alguma tentativa prévia de suicídio.

O Teste de Associação Livre de Palavras, originalmente desenvolvido por Jung na prática clínica, teve como objetivo realizar diagnóstico psicológico sobre a estrutura da personalidade do sujeito. Esse teste foi adaptado, no campo da psicologia social, por Di Giacomo (1981) e desde então vem sendo amplamente utilizado nas pesquisas sobre as representações sociais. Nóbrega e Coutinho (2003) destacam que, diferentemente dos objetivos clínicos de Jung, os pesquisadores em representações sociais visam identificar as suas dimensões latentes, mediante a configuração dos elementos que constituem a trama ou rede associativa dos conteúdos evocados em relação a cada estímulo indutor. É um tipo de investigação aberta, que se estrutura por meio da evocação de respostas dadas a partir de um ou mais estímulos indutores. Estes devem ser definidos previamente em função do objeto a ser pesquisado ou objeto da representação, levando em consideração também às características da amostra ou sujeitos da pesquisa.

Para a análise dos dados coletados através do segundo instrumento, foi elaborado inicialmente pelos pesquisadores um dicionário construído a partir das respostas dos participantes referentes aos quatro estímulos indutores. As evocações foram organizadas em categorias, com base em critérios de similaridade semântica entre as palavras. Esse procedimento teve como finalidade evitar a redundância e tornar as evocações estatisticamente significativas. Neste estudo foram utilizados quatro estímulos: (1) Ideação suicida, (2) 
suicídio, (3) eu mesmo e (4) futuro. As variáveis fixas utilizadas foram: sexo, faixa etária e presença da ideação suicida. Os participantes foram solicitados a escrever palavras após cada estímulo dado, tendo no máximo um minuto para cumprir tal tarefa (para cada estímulo). Por fim, o questionário biossociodemográfico objetivou apreender o perfil dos participantes da pesquisa, coletando informações como: idade, sexo, série, estado civil, habitação, renda familiar, religião e o conhecimento acerca da tentativa de suicídio por outras pessoas.

A coleta de dados foi realizada nas salas de aula, de forma coletiva, com duração média de vinte minutos. No momento da aplicação dos instrumentos os estudantes foram informados a respeito dos procedimentos éticos e do anonimato de sua colaboração.

Não foi realizado um encaminhamento individual aos estudantes que manifestaram ideação suicida, visto que a pesquisa assegurava o anonimato dos participantes, não sendo possível identificá-los. No entanto, foram realizadas palestras na escola sobre essa temática, nas quais os estudantes eram informados que poderiam entrar em contato com os pesquisadores caso desejassem um acompanhamento psicológico, sendo dado a esses casos um encaminhamento para a Clínica-Escola de Psicologia da UFPB.

\section{Resultados e Discussão}

Os resultados obtidos - por meio da Escala de Ideação Suicida de Beck /BSI - apontam a presença da ideação suicida em $22,2 \%$ dos adolescentes pesquisados, número significativo quando comparado com outros estudos, a exemplo do realizado por Vieira (2008), com 233 estudantes do ensino superior, o qual apresentou um índice de $11 \%$. Faz-se necessário ressaltar que a amostra analisada nesta pesquisa é constituída por adolescentes, e, de acordo com Borges e Werlang (2002), os jovens nessa fase apresentarem a ideação suicida como forma de expressar um sofrimento geralmente associado a um conflito interno, encarando a possibilidade da morte como uma solução. Ainda conforme os autores acima citados esses pensamentos podem estar apontando algo mais, que de fato ultrapassa as características próprias da adolescência. Pela análise do questionário biossociodemográfico, foi possível traçar um perfil dos participantes que apresentaram ideação suicida, o qual se encontra descrito na tabela a seguir.

Tabela 1 - Perfil biossociodemográfico dos estudantes com ideação suicida

\begin{tabular}{cccc}
\hline Variável & Níveis & N & $\%$ \\
\hline \multirow{2}{*}{ Sexo } & Masculino & 9 & 45 \\
& Feminino & 11 & 55 \\
\hline \multirow{2}{*}{ Faixa etária } & $14-16$ anos & 4 & 20 \\
& $17-19$ anos & 11 & 55 \\
Série escolar & $20-22$ anos & 5 & 25 \\
& $1^{\circ}$ ano & 5 & 25 \\
\multirow{2}{*}{ Estado civil } & $2^{\circ}$ ano & 9 & 45 \\
& $3^{\circ}$ ano & 6 & 30 \\
\hline \multirow{2}{*}{ Moradia } & Solteiro & 19 & 95 \\
& Casado & 1 & 05 \\
\hline Trabalho & Mora com os pais & 17 & 85 \\
\multirow{2}{*}{ Religião } & Mora com companheiro & 1 & 05 \\
& Mora com familiares & 2 & 10 \\
\hline & Não & 20 & 100 \\
\hline
\end{tabular}

Observou-se que dos 22,2\% com ideação suicida, $55 \%$ são do sexo feminino e encontram-se na faixa etária entre 17 e 19 anos; 45\% cursam o $2^{\circ}$ ano do ensino médio; $95 \%$ são solteiros; $85 \%$ moram com os pais; $70 \%$ afirmaram ser católicos; e $100 \%$ disseram não possuir trabalho remunerado. 
Os dados coletados através da Técnica de Associação Livre de Palavras foram processados pelo software Tri-Deux Mots e analisados pela Análise Fatorial de Correspondência (AFC), que oferece uma leitura gráfica das variações semânticas na organização do campo espacial, revelando aproximações e oposições das modalidades. É possível também apreender a atração entre as variáveis fixas (sexo, faixa etária e presença de ideação suicida) e as de opinião, que correspondem às palavras evocadas pelos sujeitos para cada um dos estímulos indutores (ideação suicida, suicídio, eu mesmo, futuro).

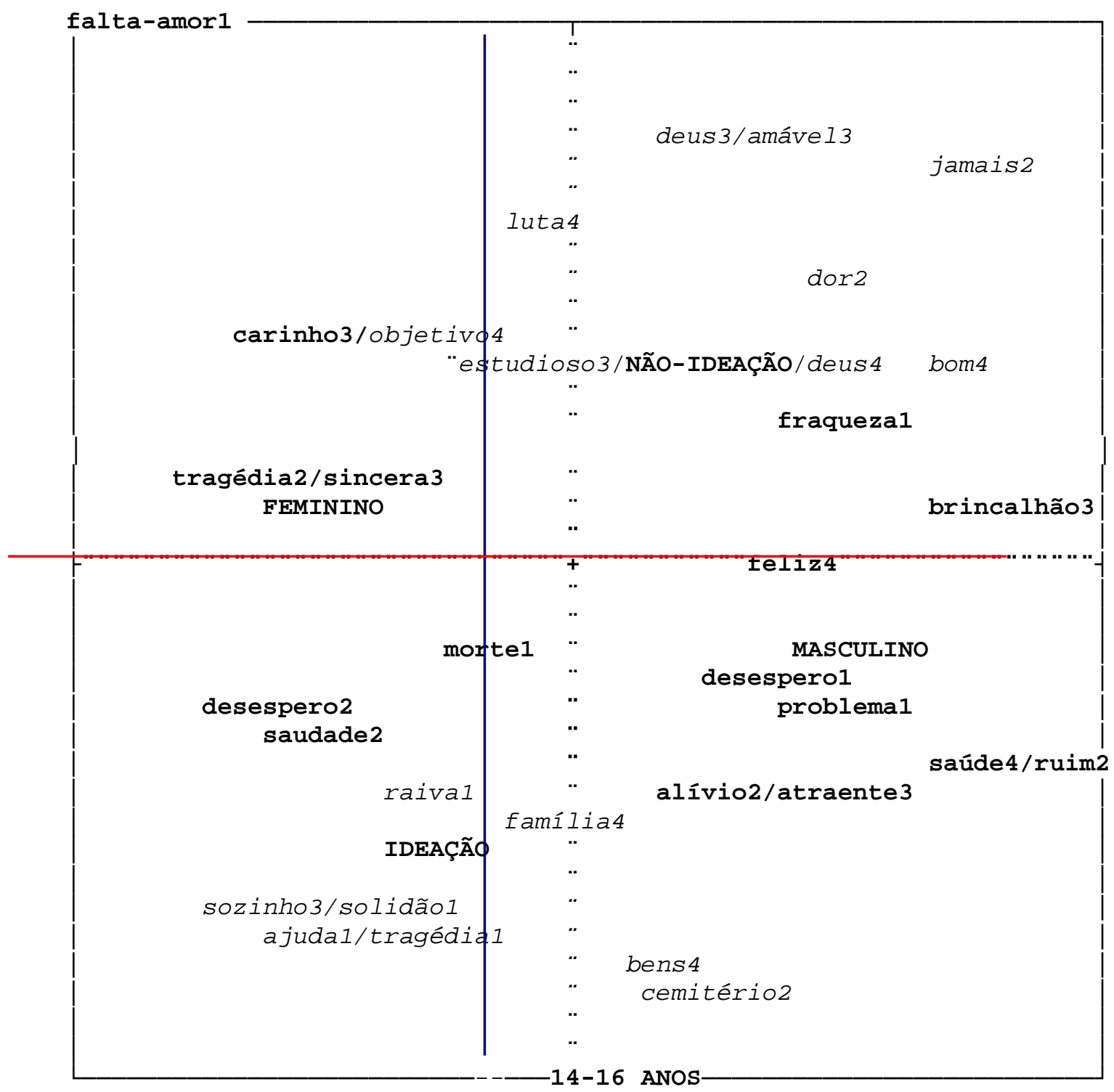

Figura 1 - Análise fatorial de correspondência das representações sociais da ideação suicida

A descrição da Figura 1 faz-se pela leitura das modalidades que correspondem às palavras evocadas ou representações, que se encontram distribuídas de maneira oposta sobre os eixos ou fatores (F1 e F2).

$\mathrm{O}$ primeiro fator (F1), em negrito, revela as mais fortes modalidades ou representações, que explicam 33,9\% da variância total das respostas. O segundo fator (F2), em itálico explica $24,6 \%$ dessa variância, que junto ao fator 1 , explica $58,5 \%$ da variância total das respostas.

Em relação ao fator 1 (F1) no lado superior esquerdo do gráfico em negrito, emerge o campo semântico correspondente às respostas evocadas pelos estudantes do sexo feminino. Para esses, a ideação suicida foi representada pelo elemento "falta de amor"; indicando que a carência afetiva contribui para os pensamentos ou ideias de morte autoprovocada. Ainda nesse mesmo eixo fatorial, 
verificam-se as palavras em negrito com terminação 2, que se referem às representações sociais do suicídio elaboradas por elas, as quais o veem como decorrente de uma atitude de "desespero" perante a vida, caracterizando uma "tragédia". A "saudade" também foi lembrada e enfatizada pelas participantes, indicando ser esse o sentimento predominante após o ato suicida. Em relação ao terceiro estímulo - eu mesmo -, verificou-se que as evocações mais representativas foram "sincera" e "carinhosa", enquanto o estímulo indutor futuro foi representado pelo elemento "objetivos".

Observou-se que as representações do comportamento suicida (ideação e suicídio consumado) ancoraram-se nos fatores desencadeantes do ato, focalizados na ausência de amor, no estado de sofrimento psíquico e desesperança do ser suicida. $O$ sentimento de saudade enfatizado pelas participantes remete ao sofrimento dos que ficam; a dor da saudade dos amigos e familiares, que sentem a perda oriunda do ato suicida. As autorrepresentações desse grupo de afiliação emergem de forma positiva, bem como as referentes às expectativas futuras, caracterizadas pelo desejo de atingir alguns objetivos.

Em contraste com essas evocações, os participantes do sexo masculino representaram a ideação suicida como uma atitude de "desespero", um ato de "fraqueza" diante de algum "problema", o que pode ser observado à direita do fator 1 , na parte inferior em negrito. O suicídio foi descrito de forma ambígua, pois ao mesmo tempo em que é visto como algo "ruim", também traz "alívio". Em relação ao estímulo indutor eu mesmo, as representações mais significativas foram "atraentes" e "brincalhões"; já as evocações mais significativas, para o estímulo indutor futuro, foram as palavras "saúde" e "feliz".

Percebe-se que esse grupo de afiliação apresentou a ideação suicida ancorada nos motivos ou razões pelos quais um indivíduo viria pensar em pôr um fím à própria vida; ou seja, diante de um problema, fraqueja e desesperadamente pensa em provocar a própria morte. Ao atribuir uma condição de fraqueza ao individuo, os participantes podem estar sinalizando dois sentidos diferentes e possíveis para o ser fraco. O primeiro como sinônimo de falta de força, de vigor, de solidez, de energia, provavelmente associado a um quadro depressivo, sendo uma manifestação predominantemente orgânica. O segundo, significando uma avaliação negativa na direção de falha ou defeito como: covardia, falta de obstinação, ou seja, o lado fraco do caráter de um ser, o que revela uma propensão a ceder a sugestões, imposições ou impressões e, nesse sentido, devendo ser encarada como manifestação psicológica.

Em relação ao suicídio consumado, observouse a existência de uma ambiguidade nas representações sociais desse fenômeno, ao qual atribuíram valores positivos e negativos. De forma semelhante, encontraram-se ambiguidades no estudo de Vieira (2008), onde o fenômeno foi descrito como um ato de coragem e covardia ao mesmo tempo, representando o fím não só $\mathrm{da}$ vida, mas, principalmente, do sofrimento vivenciado pelo indivíduo. Pode-se inferir, então, que a representação do indivíduo suicida para este grupo de pertença, ou seja, para a amostra de estudantes pesquisados, corresponde a um ser corajoso, que atenta contra sua própria vida, mas ao mesmo tempo, é alguém que está fugindo dos seus problemas, vendo na morte a saída mais fácil, caracterizando, assim, um ato de covardia.

As autorrepresentações dos estudantes do sexo masculino também emergiram de forma positiva, enfatizando características peculiares da adolescência. A respeito de suas expectativas, esses adolescentes destacaram seus desejos, suas esperanças em relação ao futuro no intuito de serem saudáveis e felizes.

Em relação ao fator 2 , na parte superior do gráfico, emergiu o campo semântico elaborado pelos participantes, que, segundo a Escala de Ideação Suicida de Beck - BSI, não apresentaram a ideação suicida. Esta foi representada, por esse grupo de afiliação, como "fraqueza", sendo o suicídio algo que representa "dor" e que, provavelmente por isso "jamais" o cometeriam. Esses atores sociais se autorrepresentaram como pessoas "amáveis", "estudiosas" e que possuem grande fé em "Deus". Para o estímulo indutor futuro, a palavra "Deus" também foi evocada, juntamente, com as evocações "bom" e "luta".

Observou-se que, para o grupo de estudantes que não atingiu o ponto de corte (16) no BSI, o comportamento suicida é representado mediante evocações, as quais indicam que essas atitudes, seja o pensamento de morte ou mesmo a morte propriamente dita, não fazem parte de suas vivências. $\mathrm{O}$ suicídio foi descrito como algo inaceitável, que eles nunca chegariam a praticar, pois ocasiona dor; esta expressão "dói tanto" pode ser entendida como oriunda do ser suicida, que estaria ocasionando o ato por esse sofrimento, 
como também pode ser a dor dos amigos e familiares, que sentem a perda. Percebe-se, nesse grupo, a presença forte da religiosidade, independentemente da crença, traduzida tanto nas autorrepresentações quanto nas expectativas futuras, ambas representadas por meio de evocações positivas.

Por fím o último campo semântico, localizado no fator 2 em itálico, refere-se às representações sociais dos participantes com idades entre 14-15 anos que apresentaram ideação suicida segundo a BSI. Para esse grupo de pertença, ela foi objetivada através dos elementos "morte" e "tragédia", enfatizando-se ainda os sentimentos de "raiva" e "solidão" sentidos pelo ser que apresenta esses pensamentos. Também foi ressaltada a necessidade de "ajuda", seja de um profissional, da família ou dos amigos. O ato suicida foi objetivado pelo elemento representacional "cemitério", enfatizando-se, dessa forma, o local para onde vão os indivíduos que o cometem. As autorrepresentações desse grupo foram objetivadas na solidão, uma vez que os participantes definiram-se como pessoas "sozinhas"; enquanto para o estímulo indutor futuro as palavras "família" e "aquisição de bens" foram as mais representativas.

Verificou-se uma quantidade maior de evocações para o estímulo indutor ideação suicida por parte desse grupo de pertença -, se comparado aos demais, caracterizando-se, provavelmente, por apresentar um maior consenso e uma maior facilidade em expor seus sentimentos e opiniões ante algo vivenciado. Os resultados assemelham-se aos encontrados por Araújo (2007), onde a ideação suicida foi representada como algo consistentemente associado a fatores relacionados à solidão, tragédia, raiva e também a palavra ajuda como elemento representativo desse fenômeno.

\section{Considerações finais}

No desenvolvimento desta pesquisa, pretendeu-se verificar as representações sociais acerca da ideação suicida elaboradas e compartilhadas por adolescentes inseridos no contexto do ensino médio, bem como investigar a presença desse fenômeno entre a população estudada. Os dados obtidos possibilitaram a realização de uma análise científica do que se denomina senso comum, baseando-se no pressuposto de que o conhecimento do senso comum propicia a compreensão do comportamento suicida a partir de um conhecimento socialmente difundido. Dessa forma, tornou-se possível conhecer os pensamentos, sentimentos e percepções dos participantes acerca dos fenômenos pesquisados.

As representações sociais da ideação suicida e do suicídio consumado giraram em torno, principalmente, das razões ou motivos pelos quais levariam $o$ indivíduo a apresentar esses comportamentos, havendo significativas diferenças entre os grupos que apresentaram ou não ideação suicida. Estes demonstraram de certa forma sua rejeição ao comportamento suicida mediante evocações de caráter negativo, enquanto aqueles apresentaram uma descrição mais detalhada dos sentimentos vivenciados pelo suicida, indicando, provavelmente, uma maior familiaridade com os temas pesquisados, já que são vividos e sentidos por eles.

Em relação à variável sexo, não houve diferenças significativas entre as representações sociais da ideação suicida e do suicídio propriamente dito, mas no que tange às autorrepresentações, algumas diferenças importantes foram observadas: os adolescentes do sexo masculino ancoraram em atributos externos (atraentes e brincalhões), enquanto elas nos aspectos subjetivos de sua personalidade (carinhosas e sinceras). Diferenças também são percebidas entre os grupos com e sem ideação, sendo o primeiro constituído por evocações de caráter negativo, diferentemente do segundo. No entanto, as expectativas futuras, de um modo geral, emergiram de forma positiva mesmo diante do grupo que apresentou ideação suicida, não havendo diferenças representativas.

$\mathrm{O}$ alto índice de adolescentes que apresentaram a ideação suicida $(22,2 \%)$ caracteriza um dado bastante preocupante, pois esse tipo de comportamento representa um fator de risco para o suicídio consumado. Por ser um ato definitivo e irreversível, a prevenção do suicídio faz-se por meio da tentativa de diminuição dos fatores de risco, tanto em nível individual quanto coletivo. Sendo assim, enfatiza-se a relevância desta pesquisa com o objetivo de detectar precocemente a ideação suicida para que possam ser traçadas estratégias de intervenção direcionadas a essa população. O significativo índice encontrado, na amostra pesquisada, demonstra a necessidade de maior atenção a esses jovens estudantes, por meio de serviços de apoio psicológico em sua formação escolar.

Por fim, acredita-se que esta pesquisa veio a contribuir de forma parcimoniosa para a 
compreensão das representações sociais da ideação suicida, tema este bastante carente de investigações. É válido assinalar a necessidade de novas pesquisas, que possam complementar ou até mesmo modificar as representações sociais aqui apreendidas. Reconhecendo as limitações concernentes ao presente estudo, espera-se, contudo, que o mesmo sirva para subsidiar políticas públicas educacionais voltadas para a saúde mental dos jovens estudantes.

\section{Referências}

Abric, J. C. (1994). Pratiques sociales et représentations. Paris, PUF.

Araújo, L. C. (2007) Ideação suicida: jovens no contexto escolar. Monografia do Curso de Psicologia, Universidade Federal da Paraíba, João Pessoa.

Barros, A. P. R., Coutinho, M. P. L., Araújo, L. F. \& Castanha, A. R. (2006). As representações sociais da depressão em adolescentes no contexto do ensino médio. Estudos de Psicologia, 23(1), 19-28.

Benincasa, M. \& Rezende, M. M.(2006). Tristeza e suicídio entre adolescentes: fatores de risco e proteção. Boletim de Psicologia, 124, 93-110.

Borges, V. R., \& Werlang, B. S. G. (2006). Estudo de ideação suicida em adolescentes de 15 a 19 anos. Estudos de Psicologia, 11(3), 345-351.

Botega, N. J. (2007). Suicídio: saindo da sombra em direção a um Plano Nacional de Prevenção. Revista Brasileira de Psiquiatria, São Paulo,29(1), 7-8.

Botega, N. J., Werlang, B. S. G., Cais, C. F. S. \& Macedo, M. M. K. (2006). Prevenção do comportamento suicida. Psico, 37, 213-220.

Brasil (2006). Ministério da Saúde. Diretrizes brasileiras para um plano nacional de prevenção do suicídio. Portaria $\mathrm{n}^{\mathrm{o}} 1.876$, de 14 de agosto de 2006.

Cassorla, R. M. S. (1998). Do suicídio: estudos brasileiros. $2^{a}$ ed. São Paulo: Papirus.

Cassorla, R. M. S., \& Smeke, E. L. M. (1994). Auto-destruição humana. Caderno de. Saúde Pública, 10 (supl. 1), 61-73.

Cibois, P. (1998) L'analyse factorielle. Paris: PUF.

Coutinho, M P. L. (2005). Depressão infantil $e$ representação social ( $2^{\text {a }}$ ed.). João Pessoa-PB: Editora Universitária UFPB.

Coutinho, M. P. L. \& Saldanha, A. A. W. (2005). Representações sociais e práticas em pesquisa. João Pessoa: Editora Universitária UFPB.
Cunha, J. A. (2001). Manual da versão em português das Escalas de Beck. São Paulo: Casa do Psicólogo.

Di Giacomo, J. P. (1981). Aspects méthodologiques de l'analyse des représentations sociales. Cabiers de Psychologie Cognitive, 1, 397-422.

Farr, R. M. (1994). Representações sociais: a teoria e sua história. Em P. Guareschi \& S. Jovchelovtih (Orgs.). Textos em representações sociais (pp. 31-55). Petrópolis: Vozes.

Holmes, D. S. (2001). Psicologia dos transtornos mentais ( $2^{\mathrm{a}}$ ed.). Porto Alegre: Artmed.

Jodelet, D. (2001). Representações sociais: um domínio em expansão. Em D. Jodelet (Org.). As representações sociais (pp.17-41). Rio de Janeiro: Editora UERJ.

Moscovici, S. (1978). A representação social da psicanálise. Rio de Janeiro: Zahar.

Moscovici, S. (2003). Representaçôes sociais: investigações em psicologia social. Petrópolis: Vozes.

Nóbrega, S. M. (2001). Sobre a teoria das representações sociais. Em A. S. P. Moreira (Org.). Representações sociais: teoria e prática (pp. 55-87). João Pessoa-PB: Editora Universitária UFPB.

Nóbrega, S. M. \& Coutinho, M. P. L. (2003). O Teste de Associação Livre de Palavras. Em M. P. L. Coutinho (Org.). Representaçôes sociais: abordagem interdisciplinar (pp.67-77). João Pessoa-PB: Editora Universitária UFPB.

Oliveira, A., Amâncio, L. \& Sampaio, D. (2001). Arriscar morrer para sobreviver: olhar sobre o suicídio adolescente. Análise Psicológica: (4), 509-521.

OMS. (2000). The World Health Report 2000. Suicide. Genebra. Obtido em dezembro de 2006 do World Wide Web http://www.who.int/topics/suicide/en/.

Pietro, D. \& Tavares, M. (2005). Fatores de risco para o suicídio e tentativa de suicídio. Incidência, eventos estressores e transtornos mentais. Jornal Brasileiro Psiquiatria, 54(2), 146154.

Silva, V. F., Oliveira, H. B., Botega, N. J., MarinLeón, L., Barros, M. B. A. \& Dalgalarrondo, P. (2006). Fatores associados à ideação suicida na comunidade: um estudo de caso-controle. Caderno de Saúde Pública, 22(9), 1835-1843.

Solomon, A. (2002). O demônio do meio dia. Rio de Janeiro: Objetiva. 
Stevenson, J. M. (1992). Suicídio. Em J. Talbott, R. Halles \& S. Yudofsky (Orgs.). Tratado de Psiquiatria. Porto Alegre: Artes Médicas.

Teixeira, A. M. F. \& Luis, M. A. V. (1997). Suicídio, lesões e envenenamento em adolescentes: um estudo epidemiológico. Revista Latino-americana de Enfermagem, 5(n ${ }^{\circ}$ esp.), 31-36.

Turecki, G. (1999). O suicídio e sua relação com o comportamento impulsivo-agressivo. Revista Brasileira de Psiquiatria, 21(suppl. 2), 18-22.

Vala, J. \& Mnteiro, M. B. (2004). Psicologia social. $1^{\mathrm{a}}$ ed. Lisboa: F.C. Gulbenkian.

Vega-Piñero, M., Blasco-Fontecilla, H., BacaGarcia, E. \& Diaz-Sastre, M. (2002). El suicídio. Salud Global, 4(2), 1-15.

Vieira, K. F. L. (2008). Depressão e suicídio: uma abordagem psicossociológica no contexto acadêmico. Dissertação de Mestrado, Universidade Federal da Paraíba, Paraíba.
Werlang, B. S. G., Borges, V. R. \& Fensterseifer, L. (2005). Fatores de risco ou proteção para a presença de ideação suicida na adolescência. Revista Interamericana de Psicologia, 39(2), 259266.

WHO - World Health Organization. (2003). International Statistical Classification of Disears and Related Health Problems. $10^{\text {th }}$ Revision. Versão online 2003. Obtido em 9 de junho de 2007 do World Wide Web : www.who.int/classification/apps/icd/icd10on line.

Sobre as autoras:

Luciene da Costa Araújo é discente do Curso de Psicologia da Universidade Federal da Paraíba - UFPB e pesquisadora do Núcleo de Pesquisa Aspectos Psicossociais de Prevenção e Saúde Coletiva /PósGraduação em Psicologia Social.

Kay Francis Leal Vieira é psicóloga Clínica-Hospitalar, mestre em Psicologia Social pela Universidade Federal da Paraíba e pesquisadora do Núcleo de Pesquisa Aspectos Psicossociais de Prevenção e Saúde Coletiva/Pós-Graduação em Psicologia Social.

Maria da Penha de Lima Coutinho é docente do Departamento de Psicologia da Universidade Federal da Paraíba e coordenadora do Núcleo de Pesquisa: Aspectos Psicossociais da Prevenção e de Saúde Coletiva/Pós-Graduação em Psicologia Social. 